Editorial Board

Chief Advisor

Balaram Pradhan

Nepal

Advisor

Dr. Upendra Gautam Nepal

Managing Editor

Bhai Raja Manandhar eRG Nepal

Kathmandu Nepal

Associate Editors

Rajendra P. Thanju

Nepal

Salil Devkota

Nepal

Dr. Rabin Shrestha Nepal

Dr. Amimul Ahsan Sr. Lecturer

Dept. of Civil Engineering

(University Putra Malaysia)

Team Member

Nepal

Dr. David J. Molden

DG, ICIMOD (International Centre for

Integrated Mountain Development)

Prof. Dr. Kiran K. Bhattarai

(Environment Specialist)

Dr. Shree Govind Shah

(Environment Specialist)

Prof. Dr. Ramesh K. Maskey

(Head, Civil and Geomatics Engineering

Dept., Kathmandu University)

Prof. Dr. Ram Manohar Shrestha

(Emeritus Prof., AIT, Bangkok, Thailand)

Norway

Dr. Krishna Kant Panthi

(Asso. Prof., NTNU)

Tore S. Jorgensen

Director,

(International Centre for Hydropower)

China

Prof. Dr. Liu Heng

Director General,

(International Centre of Small Hydropower, Hanghzou)

USA

John Garcia

(Principal : GANDA)

India

Dr. MP Sharma

(Asso. Prof., AHEC, IIT, Roorkee)

Dr. Vishnu Prasad

(Prof., Dept of Civil Engineering, MANIT, Bhopal)

\section{Climate Change: A Shadow over Nepal's Himalayas}

Climate change is the greatest threat to human existence today and it is real, not a hoax as per many scientific reports. Nepal is one of the most vulnerable countries when it comes to the impacts of it. For Nepal, water resource sector is in the fore-front to bear the brunt of its impacts. Climate change impacts have already started manifesting in the Himalayan region. Retreating glaciers and permafrostisone of the most seriously discussed issues amongst us in this context. Diminishing discharge and erratic seasonal distribution of water in the river channels downstream, among others, are probably the most fearedimplications of it.

Many research/studies have been undertaken both by government and nongovernment agencies regarding climate change impacts in Nepal. Nepal's Himalayas, which is considered to be a huge water reservoir in the form of permanent snow covering high mountains,provide perennial supply of water for numerous downstream uses, both life supporting and economy boosting.

There is not much Nepal cando about mitigation but are we doing enough for urging the international community, particularly the highly industrialized and developed nations, to cut carbon emissions on their part?How sure are we, particularly those working in this sector, about the appropriateness of our adaptation program/plans of action?These are probably some key questions that we urgentlyneed to find answers to. Without a clearly drawn action plan of adaptationthat is oriented towards our Himalayas, investments, multilateral and domestic, in hydro-based infrastructure projects will go down the drain in the long run. Many costly projects, both currently under operation and under planning, are already at great risks if our rivers are set to start shrinking and drying up as a consequence of climate change impacts. Therefore, it's hopefully not too late for the Nepalese water resource planners and developers to become seriously concerned about ourNational/ Local Adaptation Program/Plans of/for Action(NAPA/LAPAs) and more importantly about their effective implementation. Whether we have necessary financial and technical resources to ensure effective implementation of NAPA/LAPAswithin the envisaged time frame becomes a major concern in this respect.

A holistic planning for development of hydro-based infrastructure projectswith theinclusion of this new dimension of climate change related risks, thus, is the need of the hour.

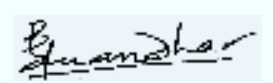

Bhai Raja Manandhar Managing Editor 